\title{
$X V$. Absorption of hydrogen by elements in the electric discharge tube
}

\section{F.H. Hewman Ph.D. F.Inst.P. A.R.C.S.}

To cite this article: F.H. Hewman Ph.D. F.Inst.P. A.R.C.S. (1922) XV. Absorption of hydrogen by elements in the electric discharge tube , Philosophical Magazine Series 6, 44:259, 215-226, DOI: $10.1080 / 14786440708633988$

To link to this article: http://dx.doi.org/10.1080/14786440708633988

曲 Published online: 08 Apr 2009.

Submit your article to this journal $\lceil\pi$

Q View related articles $\longleftarrow$

4 Citing articles: 1 View citing articles 진 
XV. Absorption of Hydrogen by Elements in the Electrit: Discharge Tube, By F. H. Newman, Ph.D., F. Inst. P., A.R.C.S., Head of the Physiss Departmert, University College, Exeter* ${ }^{*}$.

\section{Introduction.}

7 HE phenomenon of the disappearance of gas in the electric discharge-tube, and in the presence of incandescent filaments, has received much attention recently owing to its importance in technical applications. Langmuir $\dagger$ has shown that hydrogen disappears from a vacuum tube in which a tungsten filament is heated above $1000^{\circ} \mathrm{C}$. This fact has been utilized by him in the removal of the last traces of gas in valves, and the effect has been termed a "cleaning up " one. The pressures at which he worked were very low; for example, he found that the pressure in a tube was lowered to $0.00002 \mathrm{~mm}$. of $\mathrm{Hg}$. Other gases, including nitrogen and carbon monoxide, are removed in a similar manner, and molybdenum, when incandescent, has the same effect as tungsten. In all cases Langmuir found that the cooling of part of the apparatus by means of an enclosure at liquidair temperature greatly accelerated the rate of disappearance of the gases. In addition he noted an electro-chemical "clean up," which occurred at much lower temperatures of the filament, when potentials of over 40 volts were used in a way that caused a perceptible discharge through the gas.

More recently Campbell, conducting work for the General Electric Company $\ddagger$ and using incandescent filament cathodes in electric discharge-tubes, has made an exhaustive study of the "clean up" effect, and has come to the conclusion that there is much evidence for believing there exists an electrical action which is quite independent of the thermal action, and, providing the temperature of the filament is kept below that at which the chemical "clean up" occurs, the effect appears to be one dependent only on the electrical discharge. In the case of the disappearance of carbon monoxide there is proof of the conversion of this gas into carbon dioxide, and the action takes place more rapidly when part of the apparatus is cooled to liquid-air temperature. This has the effect of removing the carbon dioxide by condensation as quickly

* Communicated by the Author.

$\dagger$ Am. Chem. Soc. Journ. vol. xxxvii. (1915).

† Phil. Mag. vol. xl. (1920); vol. xli. (1921) \& vol. xlii. (1921). 


\section{Dr. F. H. Newman on Absorption of Hydrogen}

as it is formed. The presence of phosphorus vapous accelerates the rate of disappearance of all gases except the inert ones, and much lower final pressures are attained. This, the author believes, is due to the deposition of the gas on the walls of the vessel, this deposit then being covered with a layer of red phosphorus formed by the electric discharge passing through the phosphorus vapour. The covering of red phosphorus prevents liberation of the hydrogen by bombardment of the ions, and at the same time provides a new surface on which further gas can be deposited.

The problem of the disappearance of the gas is a very complicated one, owing to the many factors to be considered. The walls of the vessel and the electrodes will certainly receive some of the gas, although the latter may not disappear in its original state. There will be chemical changes occurring in the volume of the gas, such as the conversion of carbon monoxide into carbon dioxide, and, in addition, any other elements present in the discharge-tube, either in the form of vapour or solid, will affect materially the rate of disappearance of the gas and the final pressure reached.

The author* has shown previously that various substances present on the electrodes of a discharge-tube alter considerably the amount of gas that can be caused to disappear when an electric discharge is passing. In particular, phosphorus, sulphur, and iodine cause both hydrogen and nitrogen to be absorbed at a very great rate, and a high vacuum is quickly produced as a result. This action of phosphorus has been used for many years to obtain and maintain very low pressures in valves. These three elements stand out as being very effective even at high pressures, but other substances which were tested in a similar manner did not appear to absorb hydrogen. On the contrary, gas appeared to be liberated. This effect can be explained as follows. At pressures above $1 \mathrm{~mm}$. of $\mathrm{Hg}$. a certain amount of the gas in a discharge-tube becomes occluded within the walls. This gas will be liberated when the walls are bombarded by the ions producad by an electric discharge. This effect will mask any disappearance. If, however, the tube is heated almost to the softening point of glass and highly exhansted, then on admitting hydrogen at a small pressure such as $0^{-1} \mathrm{~mm}$. of $\mathrm{Hg}$., very little occlusion of the gas within the walls will take place, and on passing the electric

* Newman, Proc. Roy. Soc., A. vol. xc. (1914); Proc. Phys. Soc. vol. xxxii. (1920) \& vol. xxxiii, (1921). 
discharge practically no bydrogen will be liberated from the walls by bombardment with the ions. If there is any absorption of the gas, this effect will not be masked by the liberation of the gas from the walls or electrodes.

The object of the present work was the study of the behaviour of hydrogen in the presence of various elements in a discharge-tube when a current was passing through it. The pressures of the gas in these experiments were much lower than those used by the author in the papers quoted above, but they were much greater than those used by the previous investigators-Langmuir and the General Electric Campany.

\section{Description of Apparatus.}

At gas-pressures below $0.1 \mathrm{~mm}$. Hg. it is difficult to obtain a current through a discharge-tube unless very high potentials are used. A valve also must be placed in the circuit to make the discharge unidirectional. This entails further diminution

Fig. 1.

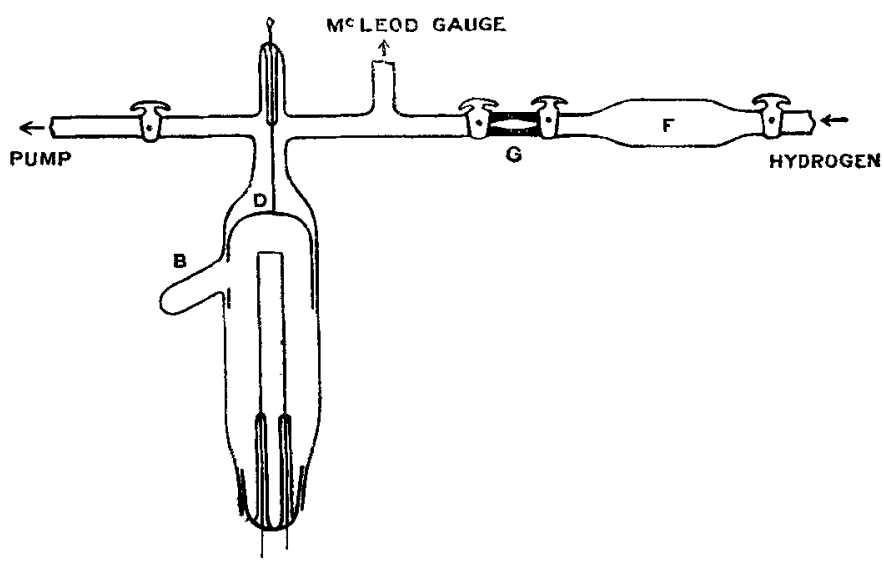

of the current. By using a Wehnelt cathode the potential required was greatly reduced. The apparaius employed is shown in fig. 1. The incandescent filament was is strip of platinum foil $5 \mathrm{~mm}$. long and $3 \mathrm{~mm}$. wide. As the discharge-tube had to be thoroughly cleaned after each experiment, the cathode was sealed in a glass stopper w hich could he removed when the tube was cleaned. This necessitated the use of tap-grease, but the vapour arising from it did not appear to affect the results at the pressures used. 


\section{Dr. F. H. Newman on Absorption of Hydrogen}

Previous experiments had shown that elements such as sodium and potassium are only effective in causing the disappearance of gas in the electric discharge-tube if the surface of the element is clean, and if it has been prepared in vacuum. Accordingly the substance under test was placed on the platinum foil forming the cathode, and after the tube had been heated almost to the softening point of glass and exhausted, the element on the foil was vaporized by passing an electric current through the latter. In this way the substance was then deposited on the inner surface of the anode $\mathrm{D}$ and an uncontaminated surface obtained. The anode was of aluminium and was cylindrical in shape, fitting very closely to the glass walls. Enclosing the cathode in this way, the effect of the surface of the glass on the absorption of the gas was minimized. A side tube B was used to contain the easily volatile elements such as phosphorus, sulphur, and iodine. An aperture was made in the anode opposite the mouth of $B$ so that the vapour of the substance from $B$ could pass through and be deposited on the inner surface of D. The pressures of the gas were measured with a Mcleod gauge. The hydrogen was prepared by the electrolysis of barium hydroxide and stored in a reservoir. This method of preparing the gas ensues great purity. Any oxygen present was removed by passing the gas through a bulb containing sodium-potassium alloy. Phosphorus pentoxide in $\mathrm{F}$ removed any water-vapour, and of course the alloy was effective in this respect also. The gas could be admitted to $G$, which was a known volume $(0.051$ c.c. $)$ enclosed between two tans. A definite volume of gas at a known pressure could thus be admitted to the discharge-tube. From observations of the pressure in the tube before and after a discharge had passed, the actual volume of gas - at atmospheric pressure - which had disappeared could be calculated.

The current through the discharge-tube was kept constant by altering the filament current, and was measured with a galvanometer. In previous experiments the quantity of electricity passing through the tube while absorption was taking place had been measured with a water voltameter, but in the present work this method was not sensitive enough.

After deposition of the substance on the anode $D$, the tube was again highly exhausted to remove any gases liberated from the volatized substance. The tube was placed in an enclosure maintained at $-40^{\circ} \mathrm{C}$. while absorption of gas was in progress. 
Observations were then taken of the changes in pressure due to the disappearance of the hydrogen when an electric discharge passed through the gas. The results obtained are shown in the accompanying table.

The accelerating potential was 94 volts, obtained by using small accumulators. The current through the tube was kept constant, and was 546 micro-amps.

Each set of readings corresponds to an electric discharge for ten minutes, except in the cases of sulphur, phosphorus, and iodine, where the observations were taken at intervals of two minutes-i.e., with sodium the pressure changed from $743 \times 10^{-3} \mathrm{~mm}$. of $\mathrm{Hg}$. to $336 \times 10^{-3} \mathrm{~mm}$. of $\mathrm{Hg}$. in ten minutes, while with snlphur the pressure was lowered from $740 \times 10^{-3} \mathrm{~mm}$. of $\mathrm{Hg}$. to $329 \times 10^{-3} \mathrm{~mm}$. of $\mathrm{Hg}$. in two minutes.

The amount of hydrogen which would be liberated from a water voltameter in 10 mins. by the same current is $39 \times 10^{-3}$ c.c. at atmospheric pressure.

As the gas may disappear into the walls of the anode even in the absence of any substance on the anode, and as the glowing filament may affect the rate of disappearance, preliminary observations were always made when an electric discharge passed through the tube without the substance present on the anode. The volnme of gas which disappeared owing to these two effects was always very small compared with that which was absorbed when the element under test was on the anode.

\section{Experimental Results.}

After each element had been tested, the tube was heated to $300^{\circ} \mathrm{C}$., and the volume of gas reliberated was calculated from the observed change of pressure. The amount thus recovered varied considerably, but was always less than that which had disappeared. This evolved gas was again absorbed when a discharge was passed, and it is evidently hydrogen in the same condition as it was before disappearance.

If, after the gas had disappeared, a fresh amount of hydrogen was admitted, the volume which disappeared on discharge was reduced. For example, with sodium and the gas pressure at $743 \times 10^{-3} \mathrm{~mm}$. of $\mathrm{Hg}$., the vacuum was reduced to $96 \times 10^{-3} \mathrm{~mm}$. $\mathrm{Hg}$. before the action ceased. Admitting a further supply of gas to the tube, the pressure fell from $743 \times 10^{-3} \mathrm{~mm}$. Hg. to $233 \times 10^{-3} \mathrm{~mm}$. $\mathrm{Hg}$. Repeating the process again, the pressure fell from $743 \times 10^{-3} \mathrm{~mm}$. Hg. to $436 \times 10^{-3} \mathrm{~mm}$. Hg., and then the 
220 Dr. F. H. Newman on Absorption of Hydrogen

\begin{tabular}{|c|c|c|c|c|}
\hline Eloment. & $\begin{array}{c}\text { Initial Gas } \\
\text { Pressure. } \\
\mathrm{mm} . \mathrm{Hg}_{\bullet} \times 10^{-3}\end{array}$ & $\begin{array}{c}\text { Final Gas } \\
\text { Pressure, } \\
\mathrm{mm} . \mathbf{H g} \times \mathbf{1 0}-3 \text {. }\end{array}$ & $\begin{array}{c}\text { Volume of Gas } \\
\text { absorbed. } \\
\text { c.c. } \times 10^{-3}\end{array}$ & $\begin{array}{l}\text { Pressure of } \\
\text { Gas at which } \\
\text { action censed. } \\
\text { mm. Hg. } \times 10^{-3} \text {. }\end{array}$ \\
\hline Sodium $\quad . . . . . . . . .$. & $\left\{\begin{array}{l}743 \\
336\end{array}\right.$ & $\begin{array}{l}336 \\
123\end{array}$ & $\begin{array}{l}28 \\
14\end{array}$ & 96 \\
\hline Potnsgium ......... & $\left\{\begin{array}{l}726 \\
3 \pm 9\end{array}\right.$ & $\begin{array}{l}349 \\
163\end{array}$ & $\begin{array}{l}26 \\
13\end{array}$ & 81 \\
\hline $\begin{array}{l}\text { Sodiun-Potassium } \\
\text { Alloy. }\end{array}$ & $\left\{\begin{array}{l}738 \\
392\end{array}\right.$ & $\begin{array}{l}392 \\
188\end{array}$ & $\begin{array}{l}23 \\
15\end{array}$ & 110 \\
\hline Sulphur ........... & $\left\{\begin{array}{l}740 \\
329 \\
145\end{array}\right.$ & $\begin{array}{r}329 \\
145 \\
58\end{array}$ & $\begin{array}{r}28 \\
13 \\
6\end{array}$ & 26 \\
\hline Phosphorus ..... & $\left\{\begin{array}{l}748 \\
352 \\
200\end{array}\right.$ & $\begin{array}{r}352 \\
147 \\
44\end{array}$ & $\begin{array}{r}27 \\
1 \frac{1}{7}\end{array}$ & 14 \\
\hline Iodine $\quad \ldots . . . . . . .$. & $\left\{\begin{array}{l}763 \\
338\end{array}\right.$ & $\begin{array}{l}038 \\
150\end{array}$ & $\begin{array}{l}28 \\
18\end{array}$ & 124 \\
\hline Arsenic $\quad \ldots . . . . . .$. & $\left\{\begin{array}{l}750 \\
394\end{array}\right.$ & $\begin{array}{l}394 \\
206\end{array}$ & $\begin{array}{l}24 \\
13\end{array}$ & 108 \\
\hline Cadmium $\ldots . . . .$. & $\left\{\begin{array}{l}744 \\
463\end{array}\right.$ & $\begin{array}{l}463 \\
321\end{array}$ & $\begin{array}{l}19 \\
10\end{array}$ & 281 \\
\hline Calcium ............. & $\left\{\begin{array}{l}731 \\
404\end{array}\right.$ & $\begin{array}{l}404 \\
308\end{array}$ & $\begin{array}{r}23 \\
7\end{array}$ & 152 \\
\hline $\operatorname{Tin} \ldots \ldots \ldots \ldots \ldots$ & $\left\{\begin{array}{l}750 \\
386\end{array}\right.$ & $\begin{array}{l}386 \\
264\end{array}$ & $\begin{array}{r}25 \\
8\end{array}$ & 131 \\
\hline Zine .................... & $\left\{\begin{array}{l}753 \\
431\end{array}\right.$ & $\begin{array}{l}431 \\
306\end{array}$ & $\begin{array}{r}22 \\
8\end{array}$ & 276 \\
\hline Thallium............. & $\left\{\begin{array}{l}732 \\
560\end{array}\right.$ & $\begin{array}{l}560 \\
399\end{array}$ & $\begin{array}{l}12 \\
11\end{array}$ & 297 \\
\hline $\left.\begin{array}{l}\text { Morcury } \\
\text { Lead }\end{array}\right\} \ldots . . .$. & Hydrogen wa & liberated and not & bsorbed. & \\
\hline
\end{tabular}

absorption ceased. There appears to be a fatigue effect whereby the actual amount of gas which can be alssorbed by any surface is limited. This fatigue effect may be due to three causes. If the disappearance of the gas depends on chemical action, the latter will occur mainly at the surfuce of the element. The formation of a chemical compound will thus protect the rest of the substance from the action, and the process will gradually cease. If, on the other hand, the effect is due to a deposition of the gaseous atoms on 
the surface, as Langmuir suggests, these atoms will diffuse slowly into the substance. The atoms arriving later will have less area on which deposition can take place. A limit to the action will be reached when the number of atoms deposited is equal to the number set free by the bombardment of the surface by the ions.

After absorption, the proportion of the hydrogen reliberated when the tube was heated to $300^{\circ} \mathrm{C}$. varied considerably in different cases, not only with different elements, but also with the same element. This is to be expected when it is remembered that the thickness of the substance deposited on the anode varied with different substances.

The accelerating potential affected to some extent the rate of disappearance of the gas and also the final pressure attained. Owing to liberation of the gas by the bombardment with the ions, the fiual pressure reached must depend on this reverse action, and the greater the accumulation of the gas on the surface of the anode, the greater will be the amount of gas evolved.

With sodium on the anode a potential of 94 volts reduced the gas-pressure from $743 \times 10^{-3} \mathrm{~mm}$. $\mathrm{Hg}$. to $123 \times 10^{-3} \mathrm{~mm}$. $\mathrm{Hg}$. in the course of 20 minutes. When the potential was lowered to 54 volts, the pressure fell from $743 \times 10^{-3} \mathrm{~mm}$. $\mathrm{Hg}$. to $476 \times 10^{-3} \mathrm{~mm}$. $\mathrm{Hg}$. in the same time-interval. The final pressures reached before absorption ceased were $96 \times 10^{-3} \mathrm{~mm} . \mathrm{Hg}$. and $202 \times 10^{-3} \mathrm{~mm}$. $\mathrm{Hg}$. respectively. The current through the discharge-tube was kept constant throughout.

The principles of the disappearance of the gas will be discussed later, but there are certain features of the phenomenon which can be traced to chemical actions.

Many of the elements tested combine with bydrogen at high temperatures to form chemical compounds which are very stable. Any chemical action occurring in the present experiments cannot be due to the heat, as the discharge-tube was maintained at $-40^{\circ} \mathrm{C}$, and the incandescent filament was always at a lower temperature than that at which Langmuir found chemical action occurred with bydrogen. The effect may be caused by "activation" of the gas, the latter assuming some modification under the action of the electric discharge. In the above experiments the amounts of gas absorbed were so small that it would be extremely difficult to detect the existence of any chemical compound in the tube. In order to increase the amount of gas absorbed, 
and test for any chemical compounds formed, a modified form of the apparatus was used, as shown in fig. 2.

Pure hydrogen could b: admitted to the discharge-tube $A$ in small volumes by manipulation of the taps $\mathrm{I}_{1}$ and $\mathrm{T}_{2}$. Two strips of platinum foil, about $10 \mathrm{cms}$. long, were sealed in the tube E. These strips fitted closely to the glass surfuce. A potential difference of 600 volts was applied between these strips by means of small accumulators. In this way the ions actually present in $\mathrm{E}$ were removed while the discharge. was procoeding in $\mathrm{A}$. The tube $\mathrm{E}$ communicated with a mercury cut-off $K$, and a $U$ tube immersed in an enclosure maintained at $-40^{\circ} \mathrm{C}$. Sodium-potassium alloy was prepared in $D$, and after the whole of the apparatus had been evacuated, the alloy was run into C. In this way a bright and clean surface was obtained on the alloy in C." A

Fig. 2.

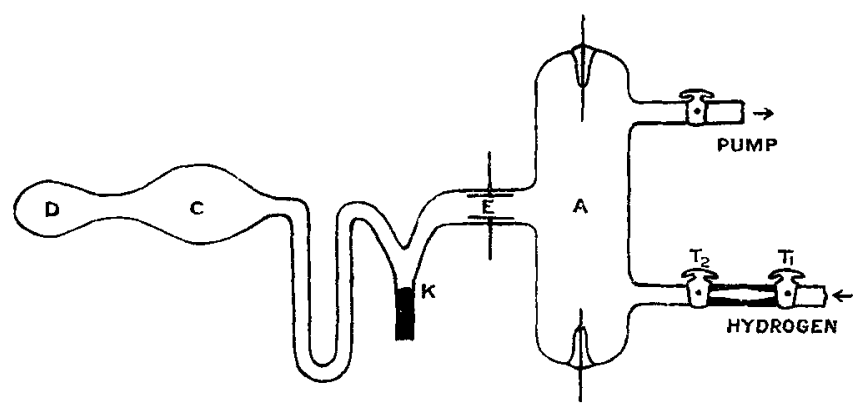

small volume of hydrogen was then admitted to $A$, the mereury cut-off preventing the gas from entering $C$ and $D$. While the electric discharge was passing in $A$, the hydrogen was allowed to enter $C$ by manipulation of the cut-off. Admitting successive volumes of hydrogen into $A$ in this way, and each time allowing communication with $\mathrm{C}$ while the discharge was proceeding, an increasing amount of active gas entered C, and an effect was observed on the surface of the alloy. At first it appeared to be covered with a thin white crystalline compound when observed through a microscope. This white layer slowly changed, on the almission of more active gas, to a dark grey-coloured deposit. To show that this surface effect was not due to impurities in the hydrogen, previous experiments were wade, the gas being admitted to $C$ without the electric discharge proceeding. There were no surface effects then, 
so it was concluded that some of the hydrogen assumes an active modification under the action of the electric discharge, and in this form it is able to form chemical compounds with the sodium and the potassium present in the alloy. The $U$ tube in the enclosure at $-40^{\circ} \mathrm{C}$. excluded the possibility of the action being due to the heat from the discharge-tube. The white crystalline compound which first appears is a mixture of the hydrides of sodium and potassium. The exact nature of the greyish-coloured product formed afterwards is unknown, but it is probably a solution of the hydrides in the alloy.

Water is evolved by an electric discharge when passed through any vacuum vessel. It comes from the glass, and would not be kept back by the trap cooled to $-40^{\circ} \mathrm{C}$.; for at that temperature water substance has a vapour-pressure of about $0 \cdot 1 \mathrm{nmm}$. $\mathrm{Hg}$. The presence of water-vapour "fouls" the surface of the alloy, but this fouling gives a black deposit on the surface which is quite different from the white crystalline layer observed in the present experiments. The black deposit consists of sub-oxides of sodium and potassium, and its appearance has been noted previously by the author*, although in that paper it was attributed to the hydrides. It has now been proved by chemical analysis that this black deposit does consist of the sub-oxides.

Sulphur was tested in the following manner:-A small piece of filter-paper, soaked in lead-acetate solution, was placed together with a small amount of the solution in $D$. The rest of the apparatus was separated from D by a mercury cut-off not shown in the figure. $\mathrm{C}$ contained sulphur which had been deposited in a thin film over the interior. After exbausting the whole of the apparatus to a pressure of about $5 \mathrm{~mm}$. of $\mathrm{Hg}$., the mercury cut-off between $\mathrm{C}$ and $\mathrm{D}$ was closed and the rest of the apparatus highly exhausted. Hydrogen was then admitted to $A$ until the pressure was about $7 \mathrm{~mm}$. Hg. While the electric discharge was passing, the mercury cut-off was opened. This was repeated many times, the pressure of the gas in A being gradually increased. Each time communication with $\mathrm{D}$ was established, any gaseous product formed in $\mathrm{C}$ was admitted to $\mathrm{D}$. In the course of a few minutes the paper soaked with the leadacetate solution turned black, showing the presence of a sulphide of hydrogen. This chemical compound must have been produced by the action of an active form of hydrogen on the sulphur. The surface of the mercury at the cut-off

* Proc. Roy. Soc. A. vol. xc. (1914). 


\section{Dr. F. H. Newman on Absorption of Hydrogen}

also lost its bright appearance. This was due to the action on it of the sulphide of hydrogen. The mercury surface remained quite clear when the sodium-potassium alloy was tested.

Sulphur and the alloy wore selected for tests because the chemical actions in these cases give rise to compounds whose effects can be noted easily. It is extremely difficult to examine phosphorus and iodine in this way owing to their high vapour-pressures. A possible test would be the comparison of the vapour-pressures before and after absorption of hydrogen had taken place.

These two experiments indicate that the chemical action is not due directly to the ions in the discharge-tube, as they were all eliminated by the charged flatinum strips before reaching either the alloy or the sulphur.

Wendt * showed that hydrogen can be activated by the passage of $\alpha$-rays through the gas, and it has been shown by the author $\dagger$ that the active modification so produced is able to react chemically with sulphur and the alloy of sodium and potassium.

\section{Discussion of Results.}

The disappearance of gas in a vacuum-tube is due probably to several principles, some of which may be fundamental. It is certain, however, that any attempt to explain the principles by the same theory would lead to conflicting results, but the processes occurring can be divided into two classes, chemical and mechanical. There is much evidence that the gas can be caused by the electric discharge to adhere to the solid parts of the discharge-tube in some manner which is at present unknown. In many cases a portion of the gas can be reliberated by heating the vessel, but no reason can be advanced for the nonreliberation of the whole of the gas which has disappeared.

Langmuir assumes in the paper previously quoted that the hydrogen in the presence of an incandescent filament undergoes dissociation. The gas shows abnormal thermal conductivity at high temperatures, due to its atomic nature. The dissociation does not occur apparently in the space round the wire, and is not due to the impacts of the gas molecules against its surface, but takes place only among the hydrogen molecules which have been absorbed by the metal of the wire. Some of the atoms leaving the wire do not meet other atoms,

* Nat. Acad. Sci. Proc. vol. v. (1919).

$\dagger$ Phil. Mag. vol. xliji. (192ஷे). 
owing to the low pressure, but diffuse into the tube cooled by liquid air, or become absorbed by the glass, and thus remain in the atomic condition. They retain all the chemical activity of the atoms. Langmuir also found that when the liquid air was removed, some of the atoms would come off the glass and recombine with other atoms to form molecules. These molecules could not be recondensed by replacing the liquid air. This gas which would not again disappear be termed a "non-recondensible" gas.

This hypothesis, which is applicable to very low pressures, cannot hold at the pressures used in the present work. The gas in the atomic condition can scarcely move from the discharge-tube for a considerable distance and still retain its atomic nature. The "non-recondensible" gas found by Langmuir is probably hydrogen in its normal state.

When nitrogen gas disappears in the discharge-tube, practically none of it can be reliberated, even when the tube is heated to the softening point. This fact indicates a striking difference between the disappearance of hydrogen and nitrogen. If chemical compounds are formed by the absorption of the gases, this difference can be explained in terms of the difference in the stability of the hydrides and nitrides produced.

The chemical action may take place between hydrogen and the vapour of the element, and also it may occur at the surface of the solid. The majority of the elements studied have such small vapour-pressures that a very small proportion of the action is due to the vapour. The active condition of the gas must be caused by the ions, although results seem to indicate that the number of active atoms or molecules in the gas is of a much higher order than the number of ions present in the gas at the instant of recombination.

The absorption is not due entirely to chemical action, as the law of constant proportions does not seem to be followed. It is of significance, however, that the rate of disappearance of the gas increases, and the final pressure attained decreases, as the temperature of the discharge vessel is lowered. This arises from the lowering of the vapourpressure of the compounds produced, with the result that the final pressure reached is lowered.

Although the formation of hydrogen sulphide in the discharge-tube by the action of the activated hydrogen on the sulphur will not explain the disappearance of the gas, it does indicate the production of a modified form of the gas which is able, possibly, to form other compounds with sulphur in addition to hydrogen sulphide.

Phil. Mag. S. 6. Vol 44. No. 259. July 1922. 
That the mechanical deposition of gas on the walls of the discharge vessel will not account entirely for the disappearance of the gas is shown by the difference in the behaviour of nitrogen and hydrogen with phosphorus, sulphur, and iodine. Practically none of the nitrogen can be reliberated by heating, but a large proportion of the hydrogen is evolved.

There is reason for believing that the modification of hydrogen is triatomic in nature: Wendt has shown in the paper previously quoted that hydrogen drawn from a tube through which an electric discharge is passing contains a small quantity of $\mathrm{H}_{3}$. Probably monatomic hydrogen is first formed, and owing to collision with neutral molecules of the gas, $\mathrm{H}_{3}$ then appears. The monatomic gas may be produced originally by the action of the swift-moving electrons on the molecules. Wendt and Grubb * have also shown that $\mathrm{N}_{3}$ is produced when an electric discharge passes through nitrogen. Thomson + found evidence of $\mathrm{H}_{3}$ in his positive-ray experiments. It is this triatomic form of hydrogen which is effective in the production of chemical compounds in the electric discharge-tube.

XVI. Molecular Thermodynamics. IT. By BeRnaRd A. M. Cavanagh, B.A., Balliol College, Oxford $\ddagger$.

\section{Molecdles, Thermodynamics, and Quantum Theory.}

\footnotetext{
Y $N$ developing a molecular treatment of the thermodynamics of dilute solutions in simple solvents, Planck $\$$ determined the form of the integration constants in the entropy function by a method which was at the time the subject of some controversy.

M. Cantor \| objected that the hypothetical transition to the gaseous state without change of the molecular composition was not even theoretically possible, since there probably existed in the liquid state, complex molecules whose existence was inseparably connected with the condensed state of the phase, and entirely incompatible with a state of bigh temperature and low pressure.

* Science, vol. lii. (1920).

† Proc. Roy. Soc. A. vol. lxxxix. (1913).

I Communicated by Dr. J. W. Nicholson, F.R.S.

\$ 'Thermodynamics,' 1917 (Trans. Ogg), pp. 225-226. Or see Phil. Mag. xliii. p. 608 (1922).

if Ann. der Phys. x. p. 205 (1903).
} 